need for therapists to modify role play techniques accordingly.

GILl SAlmon and SHIRLEY ABEll, Slade House, Oxfordshire Learning Disability Trust, Oxford OX3 7JH

\section{Audit staff and their role}

Sir: I was dismayed that Cook \& Langas' review of audit (Psychiatric Bulletin, August 1994, 18, 477) did not mention audit staff at all. I am sorry if the doctors do not have access to an audit department, but if they did many of their concerns would evaporate.

I have been a medical audit officer in general psychiatry for two and a half years. My whole raison d'etre is to work on behalf of doctors (not managers, administrators, purchasers) in setting up and carrying out audits. The main duties of audit staff are dataform design, retrieval of notes, data analysis and presentation - in other words, we take care of the administrative parts of an audit that clinicians do not have time to do. In some cases we actually do the audit as well, which educates us but not the trainees.

Audit staff have experience and skills in many different areas. Knowledge of who to see and where to go to find information in such a large organisation as the NHS is invaluable. They should also have access to, and be competent in the use of, a computer, producing good quality forms, reports and presentation materials.

So, we are here, please use us. Let's show that medical audit is effective before clinical audit arrives in earnest and audit manpower and resources are stretched to the limit.

PAUL KIRBY, Medical Audit Officer, St James's University Hospital, Leeds LS9 7TF

\section{'Age' should be included in the Trainees' Charter}

Sir: I read with interest the contents of the Trainees' Charter (Psychiatric Bulletin, July 1994, 18, 440) in particular, Clause 12, "To be treated with the consideration and respect expected of a professional colleague irrespective of status, sex or race".

Several countries, including the United States and France, provide legal protection against age and discrimination. There is no specific legislative protection against age discrimination in the United Kingdom.

Age as a discriminating factor is now a national issue in the prevailing climate of redundancies and unemployment. Although not a major problem within the medical profession as a whole, age is often perceived as a discriminating factor by a subgroup of overseas qualified doctors settled in the United Kingdom, who tend to be older than the equivalent British qualified doctors. Like myself there are several 'older' trainees of all grades in psychiatry, especially from the ethnic minorities. Being 'older' sometimes hinders the proper consideration of an individual's skills, talents, experience and potential.

The Institute of Personnel Management (IPM) holds the view that "a national campaign is essential to raise public awareness and increase the understanding of employers, employees and their representatives about the harmful business and personal implications of age discrimination in employment". The implications of age discrimination, key facts on the subject and recommendations for reducing age discrimination are clearly laid out in The IPM Codes of Practice published in 1993.

The Gwent Community Health NHS Trust, of which I am an employee, has given due recognition to age discrimination by its inclusion in the Equal Opportunities Policy.

I feel strongly that 'age' should also be included among "status, sex and race" in Clause 12 of the Trainees' Charter. It would certainly be a significant step forward and should be considered by the Collegiate Trainees Committee, Dean and Court of Electors.

FATHIMA FAROOK, Ty Bryn Adolescent Unit, St Cadoc's Hospital, Caerleon, Gwent, South Wales

Sir: I would like to thank Dr Farook for these comments; we will give them careful consideration when we revise the Trainees' Charter.

STEFfan DAvies, Chairman, Collegiate Trainees Committee

\section{Need for information about appropriate prescribing}

Sir: Mullen et al, (Psychiatric Bulletin, June 1994. 18. 335-337) found a wide variation of doses perceived as equivalent among a survey of clinicians. They suggested that this finding was disquieting and that education in this area may be inadequate but the responses of the clinicians may partly reflect the differences that are apparent between various information sources. An important source of drug information is the pharmaceutical companies. Foster (1989) pointed out the recommendations on equivalence provided by these companies differ from each other and from the literature. Schulz et al (1989) reported equivalent doses varying by $20-50 \%$ depending on which company material was considered. That the BNF offers no guidance on equivalence between oral and depot medication 